\title{
CONTROVERSY
}

\section{Bach to the future: response to: Extending preimplantation genetic diagnosis: medical and non-medical uses}

\section{R Ashcroft}

Professor Robertson sketches an elegant framework for policy evaluation and regulation of the use of preimplantation genetic diagnosis for various medical, medical related, and non-medical purposes. In criticism of his position, I argue that the distinction between policy and ethics upon which his argument relies is highly unstable, and the approach taken to ethical evaluation of particular parental interests leaves open many issues which the policy approach would hope to exclude. In conclusion I argue that while his position ultimately fails, the onus is on his critics to come up with a viable and satisfying alternative.

Correspondence to: Dr Richard Ashcroft Medical Ethics Unit, Department of Primary Health Care and General Practice, Imperial College London, Reynolds Building, St Dunstan's Road, London W6 8RP, UK ;

r.ashcroft@ic.ac.uk

Accepted

12 January 2003
$\mathrm{P}$ reimplantation genetic diagnosis (PGD) is currently very widely discussed. As Professor Robertson describes in his useful paper, the principal uses for which PGD has a clinical "indication" at present include: the avoidance of seriously disabling chromosomal or genetic abnormalities in the nuclear material and sex selection to avoid $\mathrm{X}$ linked disorders. ${ }^{1}$ These uses are somewhat controversial, in that they embroil us in debates about interventions on the embryo, and about arguably eugenic selection. None the less, there is a reasonably broad consensus in the UK medical and regulatory world that these uses are acceptable, and merit the term "clinical indication". Although there are metaphysical complexities here, the view that these uses of PGD are acceptable because they focus on the interests of the future child has respectably broad support.

More controversial are the uses of PGD to permit selecting an embryo which has a high chance of developing to become a tissue type match for an existing sibling or other blood relative who suffers from some serious condition requiring tissue donation. Although some use of PGD for such a purpose has been accepted by the UK Human Fertilisation and Embryology Authority, the official position on this remains somewhat in flux. Here the argument turns on similar issues, but additionally consideration is given to questions concerning whether PGD is acceptable where it is not positively furthering the interests of the future child, but does potentially further the interests of the relative. As with the participation of young children in non-therapeutic research, the question is whether something which is not positively in a child's interest can be tolerated or permitted if it is not positively against the child's interests. Much writing in this area has none the less conceded that this debate remains a medical ethical debate, since it turns in part on the serious medical need of the sibling, and the risk of medical harm to the future child. ${ }^{2}$

Most controversial of all are the uses of PGD for purposes which are not medical at all, such as sex selection for "family balancing" (and even more so for selection of the sex of the firstborn), and positive trait selection for non-medical reasons (the famous "deaf lesbians" case being the current focus of much debate here, although in this case PGD was not used, but instead deliberate search for a sperm donor with the required heritable trait). ${ }^{3}$ It is these uses which attract the most controversy, in part because the "plight" of the would be parents commands relatively little public sympathy.

Robertson's argument raises a number of well known issues, such as the moot status of interests of an inexistent individual or of an early embryo, the basis of the distinction between the medical and the non-medical uses of clinical techniques, and the legitimacy of pre- and postimplantation testing for early and late onset genetic disorders. There are, however, two issues he raises which seem to me to be important developments of the PGD debate.

The first is the relationship between the policy and the ethical approach to PGD. The explicit focus of Robertson's argument is on the issues raised by PGD for public policy. The policy/ethics distinction has served us well over the years, familiar instances being the Hart/Devlin debate over the law's role in promoting and defending morality (originally focused on the issue of male homosexuality) and the various applications which have been found for the theoretical work of Rawls and Dworkin in carving out a peaceful polity notwithstanding passionate disagreement about certain moral topics (such as abortion) ${ }^{4-7}$ It sometimes appears, however, that the policy/ ethics distinction is a conceptual distinction, whereas it is more plausibly taken to be a local historical achievement, which varies from jurisdiction to jurisdiction. One could argue that historical and political constructions can either discover conceptual distinctions or perhaps that historical processes create conceptual distinctions. Be that as it may, to take public policy as the proper context for handling our collective conversation, and for sifting our intuitions and calculations of consequences, does not in fact simplify very much or make it more tractable.

As is clear from Robertson's argument, the ethics/policy distinction can be put in terms of 
whether it is more important to decide what ought to be done by particular individuals or to decide what ought to be permitted. This raises two problems: firstly, does "ought" refer to obligations in our own current social conditions (and under sufficiently similar ones elsewhere) or does it refers to obligations in a just society? In other words, are we discussing ideal public policy, or public policy for the present? Call the first form of policy argument utopian and the second form constructive. No evaluation is intended by these terms: each form has its merits for some legitimate purposes. Secondly, where precisely should we draw the distinctions between the obligatory and the permissible, the permissible and the impermissible, and the impermissible and what it is obligatory not to do?

When considering the relationships between the obligatory and the permissible, either for utopian or constructive accounts of policy, it is sensible to ask what policy is trying to achieve, and what decision rules or principles should be adopted in seeking to frame it. For example, a goal of constructive policy might be to promote egalitarian goals, including gender equality, and within this it might be rational to ban PGD for sex selection on non-medical grounds-for example, grounds other than avoidance of $X$ linked disorders. Clearly this goal is inconsistent with the public policy approach favoured by Robertson, which issues in the conclusion that family balancing is permissible, and indeed, unless harm can be established in sex selection perhaps even sex selection for the first child should be permitted. Robertson's theory of public policy places great emphasis on certain liberty interests and in the avoidance of harm; and it appears that actions should be permissible unless they cause harm, with the burden of proof lying with those who would claim that harm is caused or is a serious risk. This falls within an honourable liberal tradition, but every so often we must pause and ask: even if we permit this, should we honour and respect its practice? Should we in fact do it?

The policy approach discussed here to family balancing does turn into an ethical argument, since Robertson constructs an account of what "legitimate interests" in parenting might include. Hence, the policy/ethics distinction seems to collapse both conceptually (the distinction cannot be sustained throughout the discussion) and politically (policy varies from place to place and hence we must ask about its goals and values). Where his argument becomes quite confusing is the point at which he discusses the question of creating embryos in order to permit sex selection:

The question still arises whether the desire for gender variety in children, even if not sexist, is a strong enough reason to justify creating and discarding embryos. The answer depends on how strong an interest is (see $p$ 215).

Now, earlier it had been asserted that from a policy point of view, if one thinks that "the early embryo [is] too rudimentary in development to have rights or interests" then there is "no principled objection to PGD". So on this view, the merits or otherwise of any use of PGD do not depend on the merits or otherwise of creating and discarding embryos, but rather on the purposes of the selection. So the interest based account of the permissibility of PGD for gender variety is not justified here. It does not matter how strong the interest is (and besides, what is the strength of an interest-is it the intensity with which it is felt subjectively, or is it its objective importance?), what matters is the moral status of the interest. And if so, Robertson's attempt to translate the issue of the "strength" of the interest in family balancing in different societies into a question of evidence misfires.

This takes me to the second major issue posed by Robertson's argument. The discussion of PGD for selecting a child with perfect pitch seemed to me at first bizarre and sub- sequently charming. When I was a child, the catchphrase on many middle class parents" lips was "give your child the gift of music"! It seems to me that while one might regard some genetic selection for non-medically relevant traits as the attempt to create a variety of genetic supermen, oriented, as I have suggested elsewhere, to the exigencies of performance in the neoliberal marketplace, the gift of perfect pitch might be purely that, a gift. ${ }^{8}$ The sense in which this could be so is that perfect pitch could be something purely oriented to enhancing the child's capacity for the joy and sociable pleasure music brings. And this is surely a gift which imposes no costs. For even if the child has no particular talent for musical performance, or interest in it, the child can none the less appreciate and enjoy listening to music. (Of course, perfect pitch can make it impossible to enjoy the merely competent or frankly bad performance-such as a tone deaf partner singing in the shower?)

Now it is equally clear that if PGD was anything other than a risk free procedure, using it to select for perfect pitch might be a frivolous walk with danger. Supposing that perfect pitch is genetically based, and indeed is inherited naturally in an autosomally dominant way, then there is hardly a question of engineering a child in a family without the trait expressed in either parent so that the child has the trait. It is purely a matter for couples one of whom has perfect pitch. Suppose the Bach family, transplanted into Chicago, wished to have a child, then perhaps they would be candidates. Psychologically, then, it is likely to be as much a matter of wanting the child to share family values and activities as the pure gift of a strongly enhanced capacity for musical appreciation.

Robertson is surely correct in placing this desire-and choice-into the context of all the things families do to raise their children and to make them good family members, good citizens, good musicians, and so on. And within the policy framework he describes there is nothing exceptionable about the proposal to use PGD for such purposes: there is a legitimate interest in wanting one's child to be able to appreciate music, we currently use a variety of means to try to achieve this end, PGD involves little or no additional risk, and there appears to be no strong public interest in preventing its use. Yet the limits of his policy approach are equally present. He defends minimal regulation on two grounds:

Ultimately the judgment of triviality or importance of the choice within a broad spectrum rests with the couple. If they have a strong enough preference to seek PGD for this purpose and that preference rationally relates to understandable reproductive goals, then they have demonstrated its great importance to them (see p 215).

\section{And:}

A valid concern is that such a practice might then legitimise embryo screening for other traits as well, thus moving us toward a future in which children are primarily valued according to the attractiveness of their expected characteristics. But that threat is too hypothetical to justify limiting what are otherwise valid exercises of parental choice. [...] Screening embryos for perfect pitch, if otherwise acceptable, should not be stopped simply because of speculation about what might be possible decades from now (see $\mathrm{p} 215$ ).

In other words, Robertson offers a subjective test of the strength of interest, and identifies the strength of the interest with its validity. In combination with the lack of direct harm caused by expression of this valid interest, and the remote and hypothetical nature of broader societal consequences, there is no policy objection to its use for this purpose. 
There are some rather obvious objections to this, which I set out as suggestions for future research, space not permitting much more discussion here.

Firstly, we are entitled to ask whether strongly held interests are a suitable basis either for policy or ethics. ${ }^{9}$ Not all interests are reasons for action in their own right, and not all interests command the protection of the law. It might be thought that the interest in preventing serious harm would tell us where to divide valid interests into permissible and impermissible interests; perhaps. But I am left wondering what an invalid interest is. Moreover, the construction of interest Robertson seems to use is not a purely psychological interest but commands some moral respect. Hence there seems to be an implied utilitarian ethic here, albeit a complex one making much use of rights talk. If so, then there appears, once again, room for moral discussion.

Secondly, it is at least reasonable to ask whether possessing and acting on this interest is consistent with virtue. On a pagan virtue theory, such as Aristotelian perfectionism, use of PGD for perfect pitch might be acceptable, if it permits the bearer of the gene to pursue musical perfection. But this is a complex area, rarely discussed. ${ }^{10}$

Thirdly, while we might regard individual choices and societal change as disconnected, or our evidence so poorly predictive of the connection between the two as ("from a policy point of view") better ignored, this seems to me a moot point. What sort of society would it be like if we all chose in such ways? Or wanted to (even if we were unable to do so in practice, or only few of us were)? One cannot simply dismiss this question as not susceptible to a scientific answer. It is surely just the sort of question philosophers and society at large are responsible for answering. For in the answer lies the material for bringing the answer into effect. And furthermore, different societies will have differing interpretations of the values they wish to place at the heart of their collective existence, even where there is agreement on the social theory linking individual choice and collective action and ethos.

In this commentary, I have argued that Robertson's ingenious arguments, while having much to commend them, rest on a highly problematic separation between policy and ethics, and that to the extent that the policy framework involves normative judgments these are questionable both conceptually and politically. It seems to me, however, that Robertson and others who argue within the broad framework of liberal policy and utilitarian ethics have the best arguments at present, no matter how flawed they may be, and the challenge is to come up with a positive account which will do better.

\section{REFERENCES}

1 Robertson J. Extending preimplantation genetic diagnosis: medical and nonmedical uses. J Med Ethics 2003;29:213-16.

2 Spriggs M. Savulescu J. Saviour siblings. J Med Ethics 2002;28:289.

3 Spriggs $M$. Lesbian couple create child who is deaf like them. J Med Ethics 2002;28:283.

4 Hart HLA. Law, liberty and morality. Oxford: Oxford University Press, 1967.

5 Devlin P. The enforcement of morals. Oxford: Oxford University Press, 1967.

6 Rawls J. Political liberalism. New York: Columbia University Press, 1996.

7 Dworkin R. Life's dominion: an argument about abortion and euthanasia. London: Harper Collins, 1993.

8 Ashcroft RE. American biofutures: ideology and utopia in the Fukuyama Stock debate. J Med Ethics 2003;29:59-62.

9 Sumner LW. Welfare, happiness and ethics. Oxford: Oxford University Press, 1999.

10 Hurka T. Perfectionism. Oxford: Oxford University Press, 1996.

Australasian Bioethics Association 9th Annual Conference "Virtues and Vices in Bioethics" 3-5 July 2003, Queenstown, New Zealand

Theme: Virtues and Vices in bioethics aims to capture the strengths of some excellent speakers both from North America and New Zealand. Annette Baier is a world renowned philosopher who is famous for work on the virtues and she has resided in Queenstown since her retirement from a Professorship in Philosophy at the University of Pittsburgh. Carl Elliot is widely regarded as one of North America's leading bioethicists and has links with the University of Otago where he has been a resident visiting scholar and professor.

Objectives: To bring together truly innovative thinking represented by each of the keynote speakers and a vibrant atmosphere of inquiry provided by the ABA. The fruifful mix of virtue theory, applied clinical ethics, and contemporary scholarship from a diverse set of traditions promises to create an exciting event, which will educate, refresh and inspire the attendees.

The topics discussed will include many different facets of clinical and biomedical ethics and the teaching of bioethics in universities and other tertiary institutions through Australasia.

www.dems.co.nz/bioethics 